Supporting Information

\title{
Fabrication of Few-layer Graphene Supported Copper Catalysts using a Lithium-promoted Thermal Exfoliation Method for Methanol Oxidative Carbonylation
}

Ruina Shi ${ }^{a}$, Jinxian Zhao ${ }^{\mathrm{a}}$, Yanhong Quan ${ }^{\mathrm{a}}$, Xuhui Wang ${ }^{\mathrm{a}}$, Jiangwei An ${ }^{\mathrm{a}}$, Junjie Liu ${ }^{\mathrm{b}}$, Wei Sun ${ }^{\mathrm{a}}$,

$$
\text { Zhong Lia }{ }^{\mathrm{a}} \text { Jun Ren }{ }^{\mathrm{a}, *}
$$

a Key Laboratory of Coal Science and Technology (Taiyuan University of Technology),

Ministry of Education and Shanxi Province, Taiyuan 030024, China

b Division of Nanoscale Measurement and Advanced Materials, National Institute of Metrology,

No. 18, Bei San Huan Dong Lu, Chaoyang Dist, Beijing 100029, China

Corresponding Author

*E-mail: renjun@,tyut.edu.cn 


\subsection{Characterization techniques}

TGA: Weigh an accurate amount (approximately $5 \mathrm{mg}$ ) of the sample into a ceramic crucible, and increase it from $30{ }^{\circ} \mathrm{C}$ to $950{ }^{\circ} \mathrm{C}$ at a heating rate of $10{ }^{\circ} \mathrm{C} / \mathrm{min}$ in an air atmosphere at a flow rate of $50 \mathrm{~mL} / \mathrm{min}$, and record the heating process. The mass change in the obtained thermogravimetric curve.

EIS: EIS were recorded on an electrochemical workstation (CHI660E, China). The impedance spectra were recorded by $5.0 \mathrm{mV}$ amplitude over the range of $10^{-1}-10^{5} \mathrm{~Hz}$. FT-IR: The infrared spectrum was measured using $\mathrm{KBr}$ tableting method. The specific operation is as follows: the $2 \mathrm{mg}$ sample and $200 \mathrm{mg} \mathrm{KBr}$ were ground evenly under the infrared lamp, and then the $80 \mathrm{mg}$ mixture was loaded into the mold and pressed under 6-10 MPa for 1 min to obtain the transparent sheet. Finally, the sheets were put into the Nicolet IS50 infrared spectrometer for testing.

$\mathbf{H}_{2}$-TPR: The $\mathrm{H}_{2}$-TPR measurements of the samples were performed on a Micromeritics AutoChem FINESORB 3010 analyzer. $50 \mathrm{mg}$ of sample was used for each test. Firstly, $30 \mathrm{~mL} / \mathrm{min}$ of Ar was introduced at $300{ }^{\circ} \mathrm{C}$ for $30 \mathrm{~min}$ to remove adsorbed $\mathrm{H}_{2} \mathrm{O}$ and other volatile gases on the surface of the sample. Next, the sample was cooled to room temperature, and the gas was then switched to a $10 \mathrm{vol} \% \mathrm{H}_{2}-90 \%$ Ar mixture at a flow rate of $30 \mathrm{~mL} / \mathrm{min}$. Finally, the temperature at a heating rate of $10{ }^{\circ} \mathrm{C} /$ min was elevated to $900{ }^{\circ} \mathrm{C}$.

Recycling experiments: After each typical experiment, the catalyst was recovered by centrifugation, methanol washing, and vacuum drying. The experiment was repeating five times under the same conditions to evaluate its recyclability. 


\subsection{Computational Details}

\subsubsection{Computational methods}

All DFT calculations were conducted by using the $\mathrm{Dmol}^{3}$ module in the Materials Studio 5.5 package. The generalized gradient approximation (GGA) and the exchange-correlation functional PerdewBurke-Ernzerhof (PBE) were applied. The effective core potential (ECP) was used to depict the interaction between the atomic cores and electrons for metal atoms. Other atoms were handled with an all-electron basis set. Brillouin zone sampling was carried out by using $(4 \times 4 \times 1)$ MonkhorstPack grids.

\subsubsection{Computational models}

As shown in Figure $\mathrm{S} 5(\mathrm{a})$, the $\mathrm{Cu}^{0}$ was modeled by using three-layer $\mathrm{p}(4 \times 4)$ super cells, in which the top layer was relaxed during the optimization, whereas the bottom two layers were kept frozen in the optimized bulk positions.

A three-layer $\mathrm{Cu}(111)$ surface with a $\mathrm{p}(4 \times 6)$ super cell was used for the $\mathrm{Cu}^{\delta+}$ model (Figure S5(b)). The top two layers were relaxed, whereas the bottom two layer were kept frozen, and four $\mathrm{O}$ atoms were deposited on the surface on the basis of a $\mathrm{Cu}_{2} \mathrm{O}(111)$ surface structure, followed by structural optimization to obtain the $\mathrm{Cu}^{\delta+}$ model $1^{1}$

\subsubsection{The calculation of adsorption energy}

The adsorption energy $E_{a d s}$ is deemed as a valid approach to measure the interaction strength between the adsorbate and substrate. $\mathrm{E}_{\mathrm{ads}}$ is calculated as: 


$$
\mathrm{E}_{\mathrm{ads}}(\mathrm{A})=\left(\mathrm{E}_{\mathrm{Cu}}+\mathrm{E}_{\mathrm{A}}\right)-\mathrm{E}_{\mathrm{A} / \mathrm{Cu}}
$$

where $\mathrm{E}_{\mathrm{A}}, \mathrm{E}_{\mathrm{Cu}}$, and $\mathrm{E}_{\mathrm{A} / \mathrm{Cu}}$ express the energies of the adsorbate, the $\mathrm{Cu}$-based catalyst, and the $\mathrm{Cu}$-based catalyst with adsorbate, respectively.
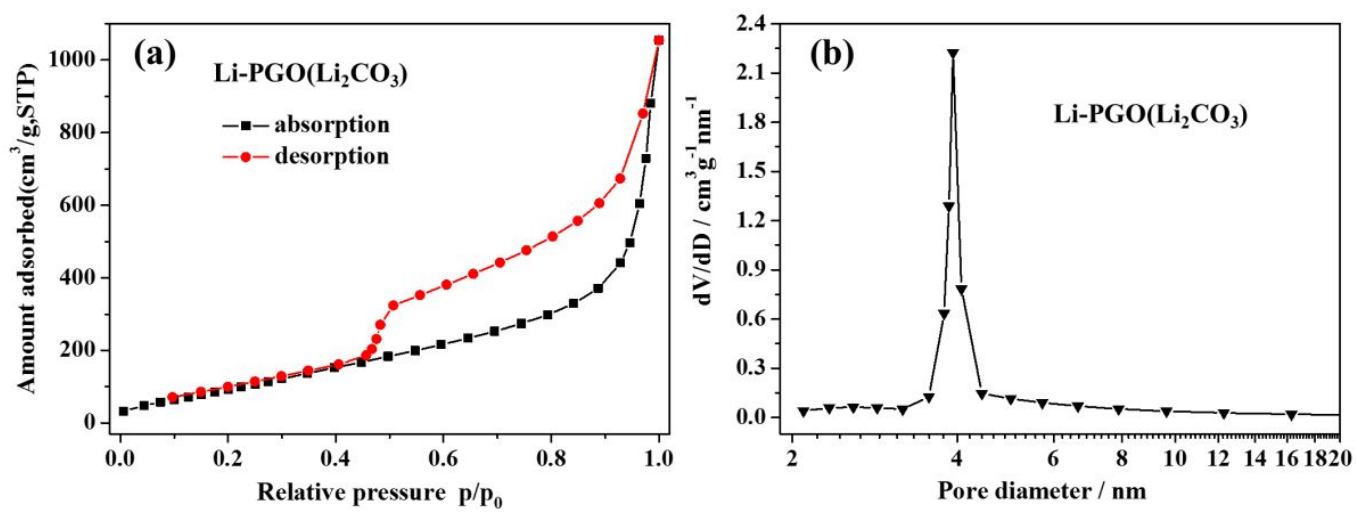

Figure $\mathrm{S} 1$. (a) $\mathrm{N}_{2}$ adsorption-desorption isotherms and (b) distributions of pore sizes of $\mathrm{Li}-\mathrm{PGO}\left(\mathrm{Li}_{2} \mathrm{CO}_{3}\right)$ sample.

(a)

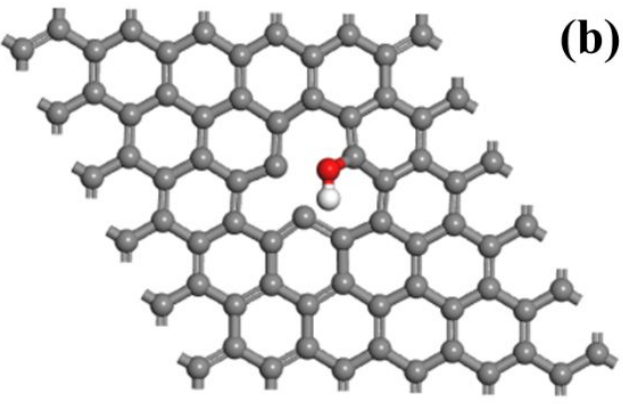

$E_{b}=445.3 \mathrm{~kJ} / \mathrm{mol}$

(b)

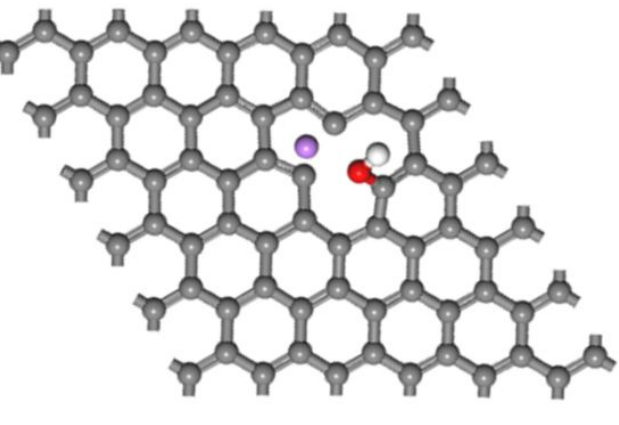

$E_{b}=370.1 \mathrm{~kJ} / \mathrm{mol}$

Figure S2. The OH-PGO (a) and OH-Li-PGO (b) surface cluster model. 


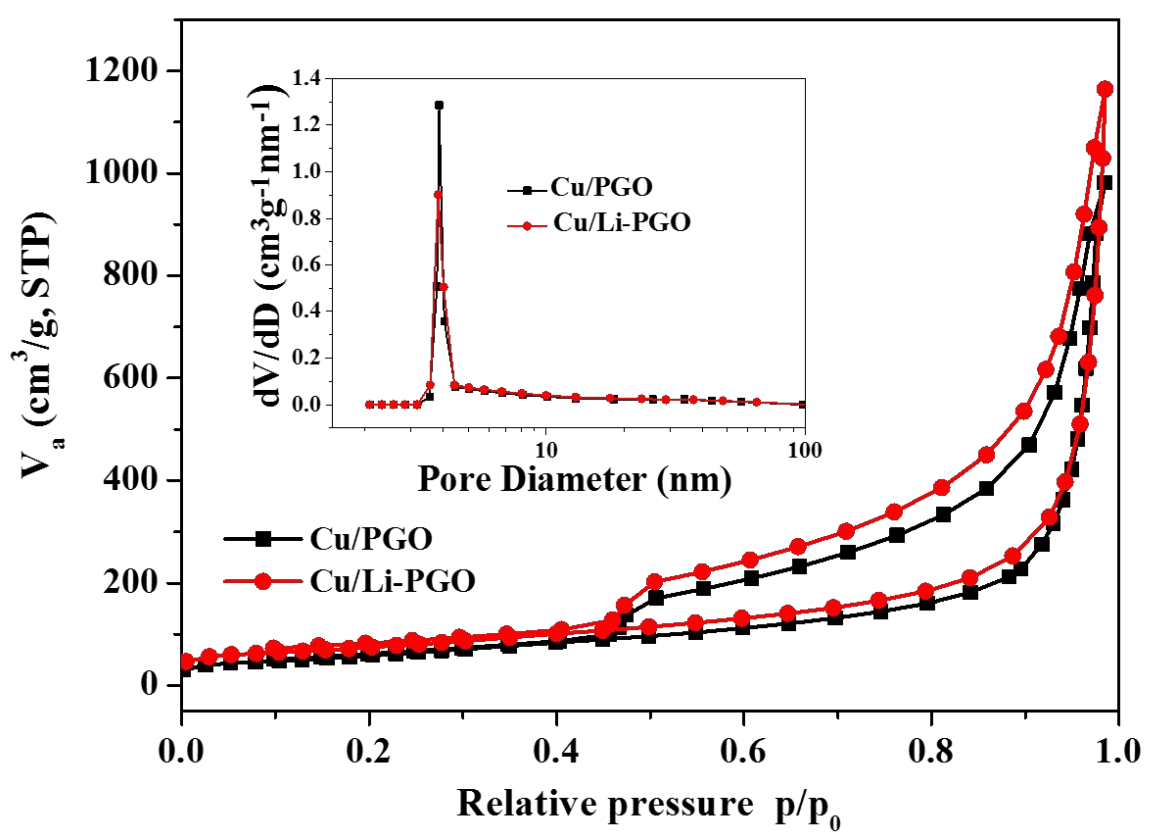

Figure S3. $\mathrm{N}_{2}$ adsorption-desorption isotherms and distributions of pore sizes of the $\mathrm{Cu} / \mathrm{PGO}$ and $\mathrm{Cu} / \mathrm{Li}-\mathrm{PGO}$ catalysts.

(a)

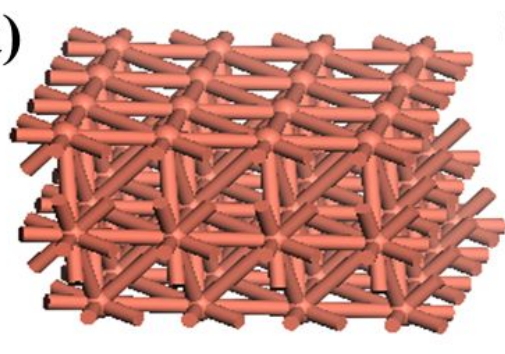

(c)

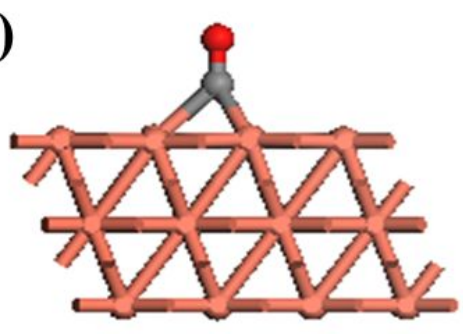

(b)

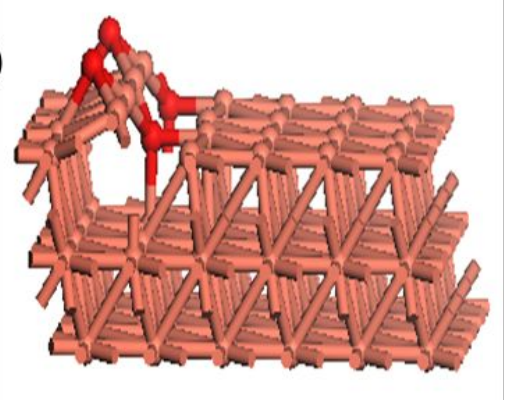

(d)

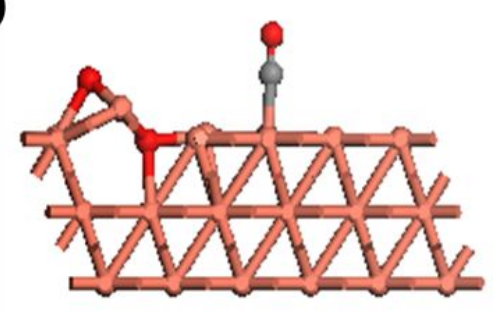

Figure $\mathrm{S} 4$. The (a) $\mathrm{Cu}^{0}$ and (b) $\mathrm{Cu}^{\delta+}$ cluster model; optimized adsorbed structures of $\mathrm{CO}$ specie on the (c) $\mathrm{Cu}^{0}$ and (d) $\mathrm{Cu}^{\delta+}$ surface (d). 
Table S1 The popping temperature of samples with different lithium content

\begin{tabular}{ccc}
\hline Sample & $\mathrm{Li}(\mathrm{wt} \%)$ & Popping Temperature $\left({ }^{\circ} \mathrm{C}\right)$ \\
\hline PGO & - & 210 \\
Li-PGO & 0.2 & 206 \\
Li-PGO-2 & 2.0 & 191 \\
Li-PGO-5 & 5.0 & 172 \\
Cu/PGO & - & 210 \\
Cu/Li-PGO & 0.2 & 205 \\
\hline
\end{tabular}

Table S2 Structural and textural parameters of the $\mathrm{Cu} / \mathrm{PGO}$ and $\mathrm{Cu} / \mathrm{Li}-\mathrm{PGO}$ samples

\begin{tabular}{cccc}
\hline Sample & $\mathrm{S}_{\text {BET }}\left(\mathrm{m}^{2} \cdot \mathrm{g}^{-1}\right)^{\mathrm{a}}$ & $\mathrm{V}_{\text {total }}\left(\mathrm{cm}^{3} \cdot \mathrm{g}^{-1}\right)^{\mathrm{b}}$ & $\mathrm{d}(\mathrm{nm})^{\mathrm{c}}$ \\
\hline $\mathrm{Cu} /$ PGO & 222 & 1.52 & 3.83 \\
$\mathrm{Cu} /$ Li-PGO & 268 & 1.80 & 3.82 \\
\hline
\end{tabular}

a, the Brunauer-Emmett-Teller surface area;

${ }^{\mathrm{b}}$, the total pore volumes (evaluated at $\mathrm{P} / \mathrm{P}_{0} 0 \sim 0.99$ );

c, the most pore diameter which was calculated by BJH method.

\section{References}

(1) An, J.; Wang, X.; Zhao, J.; Jiang, S.; Quan, Y.; Pei, Y.; Wu, M.; Ren, J. Density-Functional Theory Study on Hydrogenation of Dimethyl Oxalate to Methyl Glycolate over Copper Catalyst: Effect of Copper Valence State. Mol. Catal. 2020, 482 (June), 110667. 